\title{
The Direct Determination of Amino Acids on
} Thin-Layer Ghromatograms by Densitometry

\author{
By J. G. Heathcote and C. Haworth \\ Department of Chemistry, University of Salford, M5 4WT
}

(Received 15 July 1969)

For those engaged in sequence studies of proteins or peptides, the determination of the amino acid composition is of prime importance. The direct determination of substances resolved by t.l.c. has been shown to be feasible (Squibb, 1963; Shellard \& Allam, 1968; Dallas, 1968). According to Dallas (1968), direct densitometry is potentially the most rapid method of making t.l.c. quantitative. However, a review of the current biochemical literature showed that there were no satisfactory densitometric techniques available for the determination of amino acids that had been resolved by t.l.c. Accordingly, a study was made to develop such a method, and this communication is a brief description of the method finally chosen.

The amino acids were resolved on thin layers of MN 300 cellulose (Macherey, Nagel and Co., Düren, Germany) that had previously been washed by the technique of Haworth \& Heathcote (1969).

The solvent systems used were propan-2-olbutan-2-one-1 м-HCl (12:3:5, by vol.) for development in the first dimension and 2-methylbutan2-ol-butan-2-one-propan-1-one-methanol-wateraq. $\mathrm{NH}_{3}$ (sp.gr. 0.88) (10:4:2:1:3:1, by vol.) for development in the second dimension. The latter solvent system is a modification of one used for the qualitative separation of amino acids present in biological fluids (J. G. Heathcote \& C. Haworth, unpublished work). Although the spread of amino acids over the layer is slightly inferior to that of the qualitative system it still gave an excellent separation of the amino acids found in a protein hydrolysate (Fig. 1). The modified solvent system has the advantage, however, of giving greater density to the amino acid spots and consequently the system is capable of greater sensitivity.

The detection reagent employed was the ninhydrin-cadmium acetate reagent of Heathcote \& Haworth (1969). With the aid of this reagent $0.5 \mathrm{nmole}$ of most $\alpha$-amino acids can be detected. Particular care was taken in developing the plates that had been sprayed with this reagent. The most consistent results were obtained by heating the stained plates at $60^{\circ}$ for $15 \mathrm{~min}$. followed by storage in the dark for $4 \mathrm{hr}$. Proline and hydroxyproline were determined on a separate plate by using isatin- cadmium acetate reagent (Heathcote \& Haworth, 1969).

The spots were then scanned by reflectance densitometry at $490 \mathrm{~nm}$. for the $\alpha$-amino acids and at $620 \mathrm{~nm}$. for the imino acids. For this purpose we used the Joyce-Loebl Chromoscan instrument with thin-layer attachment.

The area of the densitometric curve was measured by using the relationship:

$$
\text { Area }=\text { peak height } \times \text { width at half altitude }
$$

The value obtained was then related to the amount of amino acid present by reading from prepared standard graphs (Heathcote \& Haworth, 1969).

The quantitative results obtained by the above procedure compared favourably with those obtained by means of automatic ion-exchange chromatography by the $24 \mathrm{hr}$. Technicon procedure. For example, for a casein hydrolysate we found the following results (expressed as g. of amino acid/ $100 \mathrm{~g}$. of casein on a moisture-free and ash-free basis) : alanine, $3 \cdot 0(3 \cdot 3)$; arginine, $3 \cdot 8(3 \cdot 9)$; aspartic acid, $7.6(7 \cdot 3)$; glutamic acid, $22.0(20.8)$; glycine, $2 \cdot 4(2 \cdot 2)$; histidine, $3.1(3 \cdot 2)$; isoleucine, $5 \cdot 6(5 \cdot 0)$;

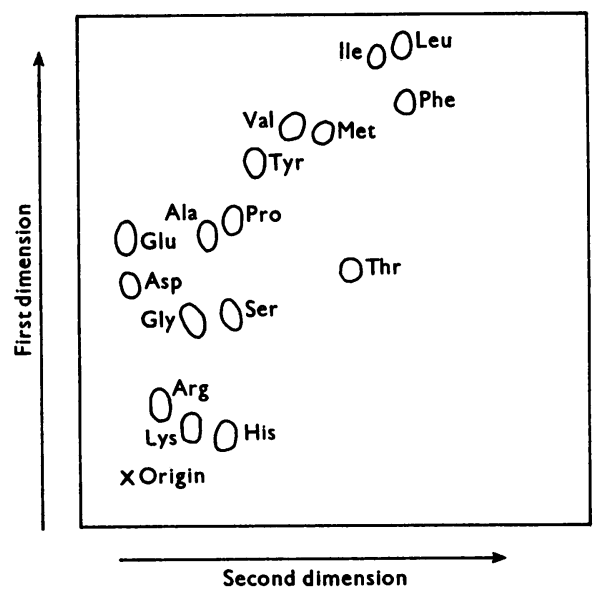

Fig. 1. Separation of amino acids in a casein hydrolysate for quantitative determination. 
leucine, 8.8 (8.2); lysine, $7 \cdot 8$ (8.1); methionine, 2.9 (3.1); phenylalanine, 4.8 (5.0); proline, $10.1(10.5)$; serine, $6.4(6.3)$; threonine, $5.5(6.9)$; tyrosine, 5.8 (4.9); valine, $6.5(6.3)$; cystine, $0.4(1.4)$; the values in parentheses are those obtained by the ionexchange procedure.

Recoveries were also good, being in the main better than $100 \pm 5 \%$ and in no case worse than $100 \pm 10 \%$.
The main advantage of this method is that only 50-250 $\mu \mathrm{g}$. of protein or peptide is required to obtain reliable quantitative results.

Dallas, M. S. J. (1968). J. Chromat. 83, 337.

Haworth, C. \& Heathcote, J. G. (1969). J. Chromat. 41, 380. Heathcote, J. G. \& Haworth, C. (1969). J. Chromat. (in the Press).

Shellard, E. J. \& Allam, M. Z. (1968). J. Chromat. 33, 347. Squibb, R. L. (1963). Nature, Lond., 199, 1216. 